\title{
Identification of genes and functional coexpression modules closely related to ulcerative colitis by gene datasets analysis
}

Jie Zhu ${ }^{1}$, Zheng Wang ${ }^{1}$, Fengzhe Chen ${ }^{1}$, Changhong Liu ${ }^{\text {Corresp. } 2}$

1 Department of Infectious Diseases, Qilu Hospital, Shandong University, Jinan, Shandong, China

2 Department of Gastroenterology, Shandong Provincial Qianfoshan Hospital, the First Hospital Affiliated with Shandong First Medical University, Jinan, Shandong, China

Corresponding Author: Changhong Liu

Email address: cfzj2019@sdu.edu.cn

Background.Ulcerative colitis is a type of inflammatory bowel disease posing a great threat to the public health worldwide. Previously, gene expression studies of mucosal colonic biopsies have provided some insight into the pathophysiological mechanisms in ulcerative colitis; however, the exact pathogenesis is unclear. The purpose of this study is to identify the most related genes and pathways of UC by bioinformatics, so as to reveal the core of the pathogenesis. Methods.Genome-wide gene expression datasets involving ulcerative colitis patients were collected from gene expression omnibus database. To identify most close genes, an integrated analysis of gene expression signature was performed by employing robust rank aggregation method. We used weighted gene coexpression network analysis to explore the functional modules involved in ulcerative colitis pathogenesis. Besides, biological process and pathways analysis of co-expression modules were figured out by gene ontology enrichment analysis using Metascape. Results. 328 ulcerative colitis patients and 138 healthy controls were from 14 datasets. The 150 most significant differentially expressed genes are likely include causative genes of disease, and further studies are needed to demonstrate this. 7 main functional modules were identified, which pathway enrichment analysis indicated were associated with many biological processes. Pathways such as 'extracellular matrix, immune inflammatory response, cell cycle, material metabolism' are consistent with the core mechanism of ulcerative colitis. However, 'defense response to virus' and 'herpes simplex infection' suggest that viral infection is one of the aetiological agents. Besides, 'Signaling by Receptor Tyrosine Kinases' and 'pathway in cancer' provide new clues for the study of the risk and process of ulcerative colitis cancerization. 
1 Identification of genes and functional coexpression

2 modules closely related to ulcerative colitis by gene

3 datasets analysis

4

6 Jie Zhu ${ }^{1}$, Zheng Wang ${ }^{1}$, Fengzhe Chen ${ }^{1}$, Changhong Liu ${ }^{2}$

$8{ }^{1}$ Department of Infectious Diseases, Qilu Hospital, Shandong University, Jinan, Shandong, P.R.

9 China

10 2Department of Gastroenterology, Shandong Provincial Qianfoshan Hospital, the First Hospital

11 Affiliated with Shandong First Medical University, Jinan, Shandong, P.R. China

*Corresponding Author:

14 Changhong Liu $^{2}$

15 Jingshi Road 16766, Jinan, Shandong 250000 (P.R. China)

16 Tel:+86-531-89268763

17 E-mail:cfzj2019@sdu.edu.cn 


\section{Abstract}

\section{Background.}

Ulcerative colitis is a type of inflammatory bowel disease posing a great threat to the public health worldwide. Previously, gene expression studies of mucosal colonic biopsies have provided some insight into the pathophysiological mechanisms in ulcerative colitis; however, the exact pathogenesis is unclear. The purpose of this study is to identify the most related genes and pathways of UC by bioinformatics, so as to reveal the core of the pathogenesis.

\section{Methods.}

Genome-wide gene expression datasets involving ulcerative colitis patients were collected from gene expression omnibus database. To identify most close genes, an integrated analysis of gene expression signature was performed by employing robust rank aggregation method. We used weighted gene co-expression network analysis to explore the functional modules involved in ulcerative colitis pathogenesis. Besides, biological process and pathways analysis of coexpression modules were figured out by gene ontology enrichment analysis using Metascape.

\section{Results.}

328 ulcerative colitis patients and 138 healthy controls were from 14 datasets. The 150 most significant differentially expressed genes are likely include causative genes of disease, and further studies are needed to demonstrate this. 7 main functional modules were identified, which pathway enrichment analysis indicated were associated with many biological processes. Pathways such as 'extracellular matrix, immune inflammatory response, cell cycle, material metabolism' are consistent with the core mechanism of ulcerative colitis. However, 'defense response to virus' and 'herpes simplex infection' suggest that viral infection is one of the aetiological agents. Besides, 'Signaling by Receptor Tyrosine Kinases' and 'pathway in cancer' 
42 provide new clues for the study of the risk and process of ulcerative colitis cancerization. 


\section{Introduction}

44 Ulcerative colitis(UC) is a subtype of inflammatory bowel disease (IBD), which is a kind of

45 idiopathic, chronic, recurrent, debilitating and nonspecific inflammatory condition, and its

46 characteristic is the alternate periods of remission and active disease (Planell et al. 2013; Strober et al. 2007). Worldwide, UC is more common than Crohn's disease (CD). Both diseases are more common in industrialized countries, particularly in North America and Western Europe, although their incidence is rising in Asia. The whole morbidity reported is between 1.2 and 20.3 cases per 100,000 persons per year, and the prevalence is between 7.6 and 245 cases per 100,000 persons per year (Danese \& Fiocchi 2011; Loftus 2004). No sex preponderance exists in UC (Bernstein et al. 2006). The peak age at onset of the disease was 30-40 years (Cosnes et al. 2011). 8-14\% of patients have a family history of IBD and first-degree relatives to patients with UC have four times the chance of developing the disease (Childers et al. 2014). Studies have confirmed that genes, environment, intestinal microorganisms and autoimmune factors are involved in the etiology of UC (Chu et al. 2016 ; Dignass et al. 2012). But, the exact pathogenesis of UC is not clear.

With the progress of genome-wide research, more and more genes closely related to UC have been discovered. The research of DNA microarrays by Lawrence et al. discovered that the differentially expressed genes (DEGs) in UC inflammatory sites, in addition to the expected variety of cytokine, chemokine related genes, and inflammation-related HNL, NGAL, proliferation-related GRO, as well as the tumor-related DD96, DRAL, MXI1, and immunerelated IGHG3, IGLL2, CD74 (Lawrance et al. 2001). An RNA Microarray study of IBD, including $6 \mathrm{UC}$ patients, found that genes related to functions of biosynthetic and metabolic processes, electrolyte transport, such as HNF4G, KLF5, AQP8, ATP2B1, and SLC16A, were significantly down-regulated in UC samples. Nevertheless, the over-expressed genes are mainly involved in such biological processes as Cell motility, Immune and inflammatory response, Antimicrobial response, Regulation of Cell growth and proliferation, and cytokine chemotaxis. 
For example, CORO1A, MMP12, TIMP1, PTGDS, CD79A, POU2AF1, TNFRSF7, IGFBP5, FSCN1, CCL11, etc (Wu et al. 2007). More recently, a similar study involving 67 UC patients showed significantly up-regulation of genes including SAA1, DEFA5\&6, MMP3\&7, S100A8\&9 (Noble et al. 2008). A meta-analysis of 2,693 UC patients reported about 30 gene loci closely related to UC, including not only TNFSF15, NKX2-3, IL12B, MST1, IL18RAP, HLA, IBD5, RNF186/OTUD3/PLA2G2E, DLD/LAMB1, IL10, CARD9, IFNG/IL26, JAK2, IL23R, but also novel FCGR2A, 5p15, 2p16, CARD9 and ORMDL3 (McGovern et al. 2010). However, genetics only explains $7.5 \%$ of the disease variation, with small predictive ability for phenotypes, and are currently limited in clinical practice (Consortium et al. 2009).

The aim of this article is to further explore the interaction of genes related to the pathogenesis of $\mathrm{UC}$ and the interaction of the enriched signal pathways, elucidating underlying pathogenic events that may contribute to find new and valuable therapeutic targets of the disease.

Gene Expression Omnibus is a public database, and dozens of gene expression datasets about UC patients are freely available, which provide very valuable information, and it could be reused to provide new insights into the molecular pathogenesis of UC. In addition, due to the small sample size in single dataset and discrepancies of the characteristics among multiple heterogeneous datasets, individual genome-wide gene expression datasets could have restricted capability in forecasting the functional gene networks. Thus, it is necessary to gather those datasets and synthetically integrate those massive data through systems biology tools, and finally receive the stable and credible results (Marques et al. 2010; Rung \& Brazma 2017; Seifuddin et al. 2013).

The robust rank aggregation (RRA) analysis is a strict tool of systems biology, which can be adopted to the comparison of multiple gene ranking lists obtained from experiments on different platforms greatly expanded the sample size, making the identification of genes related to diseases more reliable and valuable (Kolde et al. 2012). The theory of RRA is that by looking at the location of genes respectively in each ranked list and comparing it with a randomly shuffled 
95 baseline list, each gene will be assigned a p-value, and the better the location in these ranked 96 lists, the smaller the p-value will be. The final ranking of genes is based on the $\mathrm{P}$ value, and 97 logarithmic fold changes $(\log \mathrm{FC})$ can be calculated as needed to determine the importance of 98 genes together with the P-value.

99 In the current, systematic review and comprehensive integration of genome-wide gene 100 expression datasets in UC is still missing. Therefore, we performed the systematic review and 101 comprehensively integrated those genome-wide gene expression datasets through RRA to 102 identify the most probable causative genes of UC. We hope to mark out some deepening insights 103 into UC pathogenesis and provide some molecular target for therapeutic.

104 Moreover, we would use weighted gene co-expression network analysis(WGCNA) to categorise 105 those important and aberrantly expressed genes into several biologically functional modules 106 (Langfelder \& Horvath 2008; Prom-On et al. 2010), which could be biologically meaningful 107 gene clusters and play important roles in UC pathogenesis. 
108 Materials \& Methods

109 Datasets search and eligibility criteria

110 On the Gene Expression Omnibus (GEO) home page(http://www.ncbi.nlm.nih.gov/geo/), "UC

111 biopsy" was used as the search term, and the datasets in the search results were filtered according 112 to the following criteria: (1)the gene expression profile measured by microarray chip technology;

113 (2)the dataset was a comparison between active UC patients' tissue and non-UC patients' healthy

114 tissue; (3)Sample size should be at least 5; (4)The database provided raw data or gene expression.

115 Fragments Per Kilobase of transcript per Million fragments mapped (FPKM) matrix files

116 for these datasets and can be used for reanalysis. The raw data is the direct information measured

117 by instrument, in CEL format, which can be processed by R and converted into TXT format of

118 gene expression FPKM matrix. The gene expression FPKM matrix files provided by the website

119 should not have been normalized. Datasets that did not meet the above criteria are excluded.

120

121

122

123

124

125

126

127

128

129

130

\section{Robust Rank Aggregation (RRA) analysis}

The data set of a single platform is difficult to reach a large sample size, and the result is of low credibility. We used the RRA analysis method to comprehensively compare and analyze the results obtained from the genetic difference analysis of each platform, and selected the genes with strong consistency and difference, so as to make the final differentially expressed genes (DEGs) more convincing. Multiple packages of R software were applied for data processing and statistical analysis (https://www.r-project.org/) (Gentleman et al. 2004).

\section{Affy package for data preprocessing}

read.AnnotatedDataFrame(), read in the grouping information file for the samples(UC patients and controls); read.csv(), read in the annotations files of gene expression omnibus platform(GPL), including the conversion of probes to gene symbols; eset.rma $<-$ justRMA(), datExpr=exprs 
131 (eset.rma), these two-step functions apply the RMA method to normalize original files, with the 132 purpose of adjusting the overall characteristics of a single sample to make it more suitable for 133 comparison.

\section{Surrogate variable analysis (SVA) package for batch effect removing}

135

136

137

138

139

140

141

142

143

144

145

146

147

148

149

150

151

152

153

154

Batch effect is caused by different samples under different conditions such as experiment time, experiment environment, instrument, etc., and merely data normalization cannot remove batch effect. SVA package were used to remove the batch effects from different samples of the same platform (Chen et al. 2011; Leek et al. 2012). This step is performed using Empirical Bayes method, whose core function is ComBat(). Finally, gene expression value matrix files with row name as gene symbol and column name as sample number were obtained for each platform for further analysis.

\section{Limma package for differential genes analysis}

The limma package is a comprehensive package with many options for loading data, data preprocessing (background correction, intra-group normalization and inter-group normalization), and differential genetic analysis. The function of empirical Bayes linear regression method for finding differential genes is very popular. At the same time, limma package is very scalable. Both one channel and tow channel data can be analyzed for differential genes, even including quantitative PCR and RNA-seq data types (Ritchie et al. 2015).

The gene expression matrix files obtained in the last step were used for differential gene analysis between UC and Control groups by Limma package respectively, so as to acquire the DEGs of each platform (Wettenhall \& Smyth 2004). MakeContrasts() as the key function and gene rank lists of different platforms were generated. In the process, the False Discovery Rate (FDR) is calculated by benjamini-hochberg correction method, which means a adjusted P-Value, but the P-Value is still used as the basis for the significance judgment of the result. 
155 RobustRankAggreg package for RRA analysis

156 The RobustRankAggreg package was used to implement RRA analysis for Gene rank lists of

157 different platforms to generate the most valuable DEGs (Kolde et al. 2012). Core functions: list(),

158

159

160

161

162

163

164

165

166

167

168

169

170

171

172

173

174

175

176

177

178

179 rankMatrix(), aggregateRanks(). Genes with $\mathrm{P}$ value $<0.05$ and $|\log \mathrm{FC}|>1$ were selected, and the smaller the $\mathrm{P}$ value, the higher the ranking, often small $\mathrm{P}$ value of the gene corresponds to a large $|\log \mathrm{FC}|$. The final result was visualized by pheatmap package.

\section{WGCNA}

In order to clarify the main role of DEGs in the pathogenesis of UC, this method is used to cluster genes with close relationship in the same module. The weighted gene co-expression network was constructed by WGCNA package of R.

First, an appropriate gene expression FPKM matrix file is required. A number of genes and suitable samples were extracted from the raw data, and the matrix file is the FPKM of these genes for each sample. The DEGs generated in the RRA analysis were only the most important genes, and could not present the overall picture of the co-expression network. In order to cover most valuable difference genes, we adjusted the cut off value to $\mathrm{p}<0.05$ and $|\log \mathrm{FC}|>0.14$. In other studies, $|\log \mathrm{FC}|$ values are often different in order to select sufficient and relatively high value genes for WGCNA. For example, Yan et al selected $|\log F C|>0.26$ (Yan et al. 2018), while Lu et al set $|\log \mathrm{FC}|>0.585$ in order to get more differentiated genes (Lu et al. 2014). Besides, only samples from the same platform can be combined for WGCNA. To make the results more convincing, we selected GPL570 with the largest sample size, including 143 UC patients and 79 controls from 8 datasets.

Then, hclust() was used to hierarchical clustering of samples by average method and results in the initial sampletree. The following we defined sample clustering height $=80$ to remove the isolated samples from the group, so as to obtain a more hierarchical sampletree for further analysis. 
180 The core process of WGCNA is to build a scale-free distributed topological network, making the 181 functional modules developed more cohesive (Langfelder \& Horvath 2008). In the view of many 182 relevant references prove that when the scale-free fit index is greater than 0.85 , the network 183 already conforms to the scale-free network distribution (Lancu et al. 2015; Zhang \& Horvath 184 2005). We set an appropriate soft threshold power value to make the generated Scale free 185 Topology Model Fit $>0.85$.

186 Next, module identification was realized by Dynamic Tree Cut method, setting 187 minModuleSize $=30$ and deepSplit=2. Further, mergeCloseModules () , a function that can be 188 merged automatically, completes the merging of similar modules by setting the minimum height 189 for merging modules at 0.3 . Finally, some genes that could not be classified into any functional 190 module were uniformly collected into the grey60 module. Incidentally, the colors of each module 191 are randomly assigned.

\section{2 \\ Functional enrichment analysis}

Functional enrichment analysis was performed by Metascape (http://metascape.org) accord to the genes assigned to each module (Tripathi et al. 2015). In the results, the top 10 biological processes with the minimum $\mathrm{p}$ value of each module were listed, which reflected the functional characteristics of the modules.

\section{Statistical analysis}

The version of $\mathrm{R}$ used for statistical analysis was 3.5.0. In all cases, $\mathrm{P}<0.05$ was considered statistically significant. 
200 Results

201

202

203

204

205

206

207

208

209

210

211

212

213

214

215

216

217

218

219

220

221

222

\section{UC microarray datasets}

In the end, 14 datasets from 5 platforms were selected. Details of datasets were shown in Table1, including GSE number, sample size, Source types, detection platform, data file type and authors. In the study, the number of UC patients in each dataset ranged from 3 to 74, and the number of normal controls ranged from 3 to 20 . The total number of samples enrolled in the final study was 328 UC patients and 138 healthy controls.

\section{0 significant Differentially Expressed Genes (DEGs) between UC and non-UC Patients}

The top 100 up-regulated genes and the top 50 down-regulated genes by Robust Rank Aggregation (RRA) analysis were shown in Table S1 P $<6.11 \mathrm{E}-07$ and $|\log \mathrm{FC}|>1$ reminded significant differences of the top 100 up-regulated genes. Besides, the top 50 down-regulated genes had significant difference index of $\mathrm{p}<6.32 \mathrm{E}-07$ and $|\log \mathrm{FC}|>1$ (Table $\mathrm{S} 1)$.

In order to highlight the effect of the presentation, Figure 1 displayed the $\operatorname{logFC}$ for unique dataset platforms and multi-dataset platforms of the top 50 up-regulated and top 50 downregulated genes. Green represents down-regulation and red represents up-regulation. The colors deepen with the increase of $|\log \mathrm{FC}|$ respectively. The similarity of color saturation reflects the consistency of these important genes in the datasets of each platform.

The expression of the above 100 DEGs in all samples of GPL570 platform was shown in the heatmap (Figure 2). Among them, the 50 up-regulated genes mainly include: (1)Closely associated with inflammatory response, such as S100A8\&9, CXCL1\&8\&10\&11\&13, CCL19\&20, CHI3L1, IL1B, IL1RN, VNN1, IDO1; (2)MMP1\&3\&7\&9\&10\&12, PIM2, TIMP1, SERPINB5 are closely related to extracellular matrix organization process; (3)LCN2, SELL, 
223

224

225

226

227

228

229

230

231

232

233

234

235

236

237

238

239

240

241

242

243

244

245

246

CFB, CD27, CSF3R, C2, LAX1, CFI are associated with immune response; (4)DMBT1, DUOX2\& A2, and TNIP3 are associated with viral and other infections; (5)REG1A, REG3A, REG1B, PLAU, TFF1, ADM, WARS are closely related to positive regulation of cell proliferation process; (6)Other genes with scattered functions, such as PI3, OLFM4, IGFBP5, SPINK4, SLC6A14, and AQP9, are related to cell cycle progression and cell metabolism.

In addition, the other 50 down-regulated genes mainly include: (1)PHLPP2, VIPR1, APOBEC3B, PTGDR were associated with the regulation of immune inflammatory response; (2)AQP8, ABCG2, SLC26A2, CA7, BEST4, TRPM6, which involve in transmembrane transport functions; (3)CHP2, ENTPD5, SGK2, CNTFR, CLDN8, CDHR1, CNTN3, CD177, which are related to cell proliferation, migration, and adhesion; (4)SATB2, PPARG, BMP3, HEPACAM2, GUCA2B, GUCA2A, FMO5, CKB, CA1, MAOA and DHRS11 are closely related to biological processes such as cell cycle and metabolism; (5)Other genes are mainly involved in nutrient metabolism, drug and chemical reactions, and chemotactic regulation of cytokines. And a small number of genes do not yet have a clear function.

Color stratification displayed the difference of expression between the two groups. In the top several genes with the greatest difference, genes such as MMP1, REG1A and AQP8 had been confirmed to abnormally expressed in UC (Planell et al. 2013).

\section{5,344 DEGs were clustered into 7 functional modules through WGCNA}

Appropriate samples and genes were screened to construct gene expression FPKM matrix files.

Data sets must come from the same platform to be combined into a single matrix file for analysis, and we selected all samples from the GPL570 platform with the largest sample size. After adjusting the cut off value of RRA process to $\mathrm{p}<0.05$ and $|\operatorname{logFC}|>0.14,5344$ DEGs were obtained, which was more suitable for WGCNA. 
247 When soft-threshold power was set to 10 , the scale-free topology index was $>0.85$, and mean

248 connectivity was infinitely close to 0 (Figure 3A). The analysis produced 8 co-expression

249 modules, among which 7 modules contained more genes and were the main functional modules

250 (Figure 3B). The number of genes in each module ranged from 97 to 1,718. The module with the

251 largest number of genes was the blue module and the second largest module is the black module

252 with 1,398 genes. Blue and black modules also contain the largest number of the 150 most

253 important DEGs. Therefore, we believe that the pathways involved in the two modules dominate

254 the occurrence and progress of UC. The detailed gene names were listed in Table S2. The

255 network heatmap plot showed that these major modules maintain a good independence from

256 each other (Figure 3C).

257

258

259

260

261

262

263

264

265

266

267

268

269

270

\section{Co-expression modules were enriched to obtain significant pathways}

Table 2 listed the functional enrichment analysis results of 7 major co-expression modules. Biological processes from were ranked by $\log 10(\mathrm{P})$, and having the greatest $|\log 10(\mathrm{P})|$ was considered critical.

The genes of blue module were significantly enriched in 'extracellular matrix organization, lymphocyte activation, blood vessel morphogenesis, leukocyte migration and inflammatory response'. And 'nucleobase-containing small molecule metabolic process, small molecule catabolic process, isoleucine degradation' were the most important pathways enriched in black module. Besides, the genes of salmon module were mainly enriched in the biological processes of 'interferon signaling, defense response to virus and herpes simplex infection'. Cyan module was enriched into functional pathways involved in multiple fields, including protein regulation, neutrophil immunity, tyrosine kinase pathway, cancer-related pathways and many other aspects. In addition, the enriched pathways of Grey60 and midnightblue modules were closely related 
271 to inflammatory response, while the 'Cell Cycle' and 'Cell Cycle Checkpoints' were the results 272 of green module functional enrichment (Table2). 


\section{Discussion}

274 UC is a type of IBD that affects the large intestine and colon. The pathogenesis of UC is

275 complex and remains largely unknown. It is believed that genetic features, the immune response

276 to microbial dysbiosis, mucosal immune response and environmental factors contribute to the

277 pathogenesis of UC (Danese \& Fiocchi 2011). Though many genes have been found be involved

278 in UC, the gene networks associated with the etiology of UC has not been clearly defined.

279

280

281

282

283

284

285

286

287

In this study, 14 genome-wide gene expression datasets were finally included, which involved a total of $328 \mathrm{UC}$ patients and 138 healthy controls. Integrated analysis using the RRA method identified quite a few crucially up-regulated or down-regulated genes (Table 1\&Figure 1). Some of those genes are novel UC gene signatures and their molecular roles in UC pathogenesis are still largely unknown. These abnormally expressed genes may be therapeutic targets for UC and need further research.

The WGCNA clustering criteria have a great biological significance which have been widely used to explore the molecular mechanisms of various diseases (Yan et al. 2018), including IBD (Lin et al. 2018; Xie et al. 2018). In our study, the expressions of 5344 UC associated genes obtained from the RRA analysis were used in the WGCNA analysis, together with they were classified into 7 co-expression biologically functional modules (Figure 3B), which highlighted some new insights into the pathogenesis of UC at a systems level.

By functional enrichment analysis of the modules, we revealed several significant pathogenic mechanisms closely related to UC. In the absence of clinical traits, the importance of module is often judged by the number of genes they contain. The blue and black modules both have more than 1000 genes, and contain the largest number of top 150 genes, which are considered to be the two most important modules.

To further understand the significance of these functional modules in the pathogenesis of UC, enrichment analysis was performed using Metascape. The importance of pathways is based on 
298

299

300

301

302

303

304

305

306

307

308

309

310

311

312

313

314

315

316

317

318

319

320

321

322

323

Log10(P) values. Important pathways in important modules probably have the strongest correlation with the symptoms or pathophysiology of UC. The enrichment analysis of genes in the blue module mainly involved in 'extracellular matrix organization, lymphocyte activation, blood vessel morphogenesis, leukocyte migration' which relevant to inflammatory responses revealed that inflammatory pathway occupies a core position in various pathways related to UC. Extracellular matrix can regulate inflammation, healing and fibrosis. The intestinal extracellular matrix is comprised of various macromolecules, including glycoproteins such as collagens, vitronectin, fibronectin and matricellular proteins. A recent study has reported that extracellular matrix organization strongly promotes the occurrence of Intestinal fibrosis which is common in IBD (Latella et al. 2014; Wynn \& Ramalingam 2012). The black modules with the second largest number of genes and the enriched functional pathways mainly include 'nucleobasecontaining small molecule metabolic process, small molecule catabolic process, isoleucine degradation'. The regulation of metabolism of various small molecular substances suggests that many pathways and metabolism are active in tissue cells when UC is activated. 'Cell Cycle' and 'Cell Cycle Checkpoints' were the most outstanding pathways of Green module. One study pointed out that the cell cycle regulates the immune, tolerance and autoimmunity functions of $\mathrm{T}$ cells, and the excessive inflammation of IBD is the loss of immune tolerance caused by abnormal regulation of the cell cycle (Sturm et al. 2004). The enrichment results of Cyan module pathway can be seen that immune response-related pathways are still common and the localization of a large number of proteins inside and outside the cell once again indicates the activity of cell metabolism. In addition, 'pathway in cancer' process conforms to the recognized fact that UC and colorectal cancer (CRC) are closely related. Studies have shown that 8 to 10 years after diagnosis of UC, the risk of CRC begins to increase (Yashiro 2014). Tyrosine kinase receptor pathway, which regulates cell proliferation and differentiation and promotes cell survival, has been closely associated with CRC (Herr et al. 2018). Meanwhile, it has been reported that tyrosine kinase receptor RON is highly expressed in UC mucosa (Hirayama et al. 2007). 
324 Therefore, we believe that tyrosine kinase pathway plays an important role in the occurrence of 325 UC canceration.

326

327

328

329

330

331

332

333

334

335

336

337

338

339

340

341

342

343

344

345

346

347

348

349

350

Moreover, there are obvious similarities between the pathway enrichment results of grey60 module and midnigntblue module. The former chiefly include 'myeloid leukocyte activation, inflammatory response, response to bacterium'. The latter also focuses on the fields of 'inflammatory response, immune response'. Numerous studies have demonstrated the association between clostridium difficile infection and UC. Clostridium difficile toxins may lead to an enhanced inflammatory response in the presence of Clostridium difficile infection (Martinelli et al. 2014). With regard to other bacteria, salmonella and campylobacter infections have also been noted to cause an exacerbation of IBD (Malik 2015; Singh et al. 2009). The functional enrichment pathways of salmon module mainly involve in 'interferon signaling, defense response to virus and herpes simplex infection', of which 'interferon signaling' is the most important. There were some observational studies on the link between Interferon Signaling and UC. It is generally known that IFN-gamma plays a key role in the early steps of installation of inflammation, promoting monocyte recruitment and activation, and inducing the expression of other inflammatory cytokines. IFN-gamma expression was increased in the pouch mucosa of UC patients compared with controls, and thus it seems to play a pivotal role in UC patients (Leal et al. 2010). Interferon signaling has been identified as a central aspect of innate immune response which induces a wide variety of antiviral proteins against pathogens infection. Moreover, interferon signaling play a crucial role in the response to herpes virus infection by antagonizing viral replication and spread (Noisakran \& Carr 2001; Su et al. 2016). This reminds us that the occurrence of UC is probably a sequential process of herpes simplex infection-defense response to virus-interferon signaling in a part of patients. A study reported corticosteroid refractory patients may benefit from antiviral therapy (Shukla et al. 2015). This subgroup of patients who were refractory to corticosteroid was likely to undergo above-mentioned sequential process continuously. Therefore, screening for herpes virus infection, prompt diagnosis and antiviral therapy may effectively relief these patients' condition and reduce colectomy risk. However, the 
351

352

353

354

355

356

357

358

359

360

361

362

363

364

365

366

367

368

369

370

371

372

373

374

375

376

377

molecular mechanisms underlying the roles of nucleobase-containing small molecule metabolic process in UC are still poorly understood and need to be elucidated in the future.

RRA analysis in the study identifies a large amount of significant DEGs that were drastically upregulated or down-regulated, plenty of which have been reported in previous articles. We listed top 100 DEGs in the visualization operation to show the reliability of the results. The most significant causative genes are likely to be contained in the top 100 genes and need further experimental verification. Therefore, in our discussion, we will focus on the genes that are considered to be closely associated with the occurrence and development of UC.

MMP1, REG1A and AQP8 have been reported in related literatures (Planell et al. 2013). MMP1, which belong to metal dependent enzymes family, is known as interstitial collagenase involved in extracellular matrix turnover (Fanjul-Fernandez et al. 2009). MMP1 expression increased in the colonic mucosa of UC patients compared to normal controls, and the mucosa up-regulation of MMP1 correlated with the severity of disease in UC (Wang et al. 2009). There is growing evidence that MMP-1 reflect acute tissue injury and involved in the initial steps of ulceration in UC and new blood vessel formation, but the molecular mechanism underlying its effects remains unclear (McKaig et al. 2003; Wang \& Yan 2006). In the previous literature it has been pointed out by several authors that Abnormally high expression of REG1A is present in the colonic mucosa in UC patients, but its precise molecular mechanism is far from being completely understood (Planell et al. 2013). Currently several researches reported that AQP8 play important roles in gastrointestinal diseases, including UC. The expression of AQP8 is a marker of normal proliferating colonic epithelial cells and AQP8 are closely connected with fluid transport in colon (Zhao et al. 2016). A study reported that AQP8 expression reduced in the ileum of UC patients while AQP8 was dramatically induced in the colon of UC patients (Zahn et al. 2007). However, a study with larger number of samples found that the AQP8 expression was markedly decreased in UC colon tissue compared to healthy subjects in agreement with the our results (Min et al. 2013).The decrease of AQP8 may lead to the disorder of colonic mucosal fluid absorption and reduce the secretion of intestinal tract, but its molecular mechanism is poorly 
378

379

380

381

382

383

384

385

386

387

388

389

390

391

392

393

394

395

396

397

398

399

400

401

402

403

understood (Calamita et al. 2001; Elkjaer et al. 2001). High expression of DUOX2 and DUOXA2 have been shown in patients with active UC, especially where inflammation is prominent. Both of them are regulated by inflammation and crypt-by-crypt basis in UC tissues, which can increase the production of $\mathrm{H}_{2} \mathrm{O}_{2}$. This process can enhance innate defense, but has the risk of potential DNA damage (MacFie et al. 2014). Studies have confirmed that DMBT1 and IL-22 mRNA are obviously highly expressed in UC mucosa, and have a significant correlation. Il-22 increased DMBT1 expression by stimulating STAT3 and NF-KB. This process is likely to have an important effect on the innate immunity of UC mucosa (Fukui et al. 2011). A study of 32 UC patients found that the detected levels of MMP-9 and LCN-2 in feces of patients with active UC were significantly increased, and that fecal MMP-9 could be a reliable biomarker of IBD activity (Buisson et al. 2018). Coincidentally, another report suggested that Serum LCN2 level significantly increased in patients with active $\mathrm{UC}$, and it can serve as a biomarker of active UC (Stallhofer et al. 2015).

Among the significantly down-regulated genes, the high ranking ABCG2 also demonstrated low expression in patients with active UC in a previous study. ABCG2 is an efflux transporter involved in mucosal barrier function, low expression of which may increase the risk of tissue exposure to carcinogens, bacterial toxins and drugs (Englund et al. 2007). There are also some genes with significant differences, such as HMGCS2 and PCK1 are novel gene signatures of UC, but still lack of direct experimental evidence. Therefore, their relationship and value with UC need to be validated in future studies.

As mentioned above, this study creatively applied the RRA method to comprehensively analyze the DEGs of large samples from multiple platforms. The important DEGs filtered out are more reliable, and the functional distribution of the DEGs is more concentrated, which is conducive to clustering clearer functional modules in the process of WGCNA, so as to reveal an intimate pathway network with UC. The results of our study on important genes are compared with the results of other similar studies in Table S3. It can be found that in some studies, the DEGs of 
404

405

406

407

408

409

410

411

412

413

414

415

416

417

418

419

420

421

422

423

424

425

426

427

428

429

430

RNA microarray between UC and control group have a great overlap with our result, or at least a similarity in functional distribution.

Since the sample size of our study is larger, the results are more comprehensive. Some unreported genes still have considerable research value due to their homology with many genes that have been confirmed to be closely related to UC in gene function (Kobayashi et al. 2013; Noble et al. 2008; Planell et al. 2013; Wu et al. 2007). Compared to other data re-analyses researches on UC, almost all of the studies were conducted directly by functional clustering for a large number of DEGs to display the main mechanisms of the disease, which can not reflect the importance of the individual genes (Feng et al. 2017; Song et al. 2018). We innovatively used RRA to summarize and analyze the differential genes in multiple data sets to obtain the likely important causative genes of UC.

Regarding this study, findings are consistent with many previous research conclusions and current mainstream views, which reflects the reliability of research methods and results.

However, due to various reasons, the research has some limitations. Firstly, because the raw data does not provide enough information about clinical traits and disease outcomes of samples, the correlation degree between modules and clinical traits cannot be analyzed by WGCNA method, which is limited in the judgment of module importance. Secondly, as for the setting of cut off value, $\mathrm{p}<0.05$ is considered to have statistical significance. $\operatorname{LogFC}$ is set based on the similar studies and the appropriate number of genes needed for the next analysis. The difference in the value set makes a difference in the results, but not in the essence. Third, the comprehensive analysis of multiple data sets is conducive to the selection of genes with relatively consistent differences for key research. However, there are differences in experimental conditions and sample composition of different data sets, which may cause some valuable information to be cleared in the data processing. Finally, this study only delineates the possible range of closely related genes through bioinformatics method, showing the most important pathways related to the pathogenesis. The results still need to be verified by specific experimental research, and provide help for the progress of disease diagnosis and treatment. 


\section{Conclusions}

433 Bioinformatics analysis helps us narrow the scope of our research, which deepens the

434 understanding of the molecular mechanism and provides theoretical foundation for molecular

435 target therapy. The biggest characteristic of this study is that in the pathogenesis of UC,

436 immunity and infection are the two most important factors. We suspect that the two are most

437 likely to be cause-and-effect in the process of disease initiation and progression, which is a hot

438 topic in medical research at present. Herpesvirus infection-viral response-interferon pathway

439 may be the trilogy of corticosteroid refractory UC patients, who are necessary to accept antiviral

440 therapy.

441 We can use this research as the basis for further clinical specimens experiment to verify these

442 genes and pathways, which may lead to future insights into disease pathogenesis, diagnosis, and 443 treatment. 


\section{References}
Bernstein CN, Wajda A, Svenson LW, MacKenzie A, Koehoorn M, Jackson M, Fedorak R, Israel D, and Blanchard JF. 2006. The epidemiology of inflammatory bowel disease in Canada: a population-based study. Am J Gastroenterol 101:1559-1568 DOI 10.1111/j.1572-0241.2006.00603.

Buisson A, Vazeille E, Minet-Quinard R, Goutte M, Bouvier D, Goutorbe F, Pereira B, Barnich N, and Bommelaer G. 2018. Fecal Matrix Metalloprotease-9 and Lipocalin-2 as Biomarkers in Detecting Endoscopic Activity in Patients With Inflammatory Bowel Diseases. J Clin Gastroenterol 52:e53e62 DOI 10.1097/mcg.0000000000000837.

\section{Calamita G, Mazzone A, Bizzoca A, Cavalier A, Cassano G, Thomas D, and Svelto M. 2001.} Expression and immunolocalization of the aquaporin-8 water channel in rat gastrointestinal tract. Eur J Cell Biol 80:711-719 DOI 10.1078/0171-9335-00210.

Chen C, Grennan K, Badner J, Zhang D, Gershon E, Jin L, and Liu C. 2011. Removing batch effects in analysis of expression microarray data: an evaluation of six batch adjustment methods. PLoS One 6:e17238 DOI 10.1371/journal.pone.0017238.

Childers RE, Eluri S, Vazquez C, Weise RM, Bayless TM, and Hutfless S. 2014. Family history of inflammatory bowel disease among patients with ulcerative colitis: a systematic review and metaanalysis. J Crohns Colitis 8:1480-1497

$\mathrm{DOI}$ 0.1016/j.crohns.2014.05.008.

Chu H, Khosravi A, Kusumawardhani IP, Kwon AH, Vasconcelos AC, Cunha LD, Mayer AE, Shen Y, Wu WL, Kambal A, Targan SR, Xavier RJ, Ernst PB, Green DR, McGovern DP, Virgin HW, and Mazmanian SK. 2016.Gene-microbiota interactions contribute to the pathogenesis of inflammatory bowel disease. Science 352:1116-1120

DOI 10.1126/science.aad9948. 
Consortium UIG, Barrett JC, Lee JC, Lees CW, Prescott NJ, Anderson CA, Phillips A, Wesley E, Parnell K, Zhang H, Drummond H, Nimmo ER, Massey D, Blaszczyk K, Elliott T, Cotterill L, Dallal H, Lobo AJ, Mowat C, Sanderson JD, Jewell DP, Newman WG, Edwards C, Ahmad T, Mansfield JC, Satsangi J, Parkes M, Mathew CG, Wellcome Trust Case Control C, Donnelly P, Peltonen L, Blackwell JM, Bramon E, Brown MA, Casas JP, Corvin A, Craddock N, Deloukas P, Duncanson A, Jankowski J, Markus HS, McCarthy MI, Palmer CN, Plomin R, Rautanen A, Sawcer SJ, Samani N, Trembath RC, Viswanathan AC, Wood N, Spencer CC, Bellenguez C, Davison D, Freeman C, Strange A, Langford C, Hunt SE, Edkins S, Gwilliam R, Blackburn H, Bumpstead SJ, Dronov S, Gillman M, Gray E, Hammond N, Jayakumar A, McCann OT, Liddle J, Perez ML, Potter SC, Ravindrarajah R, Ricketts M, Waller M, Weston P, Widaa S, Whittaker P, Attwood AP, Stephens J, Sambrook J, Ouwehand WH, McArdle WL, Ring SM, and Strachan DP. 2009. Genome-wide association study of ulcerative colitis identifies three new susceptibility loci, including the HNF4A region. Nat Genet 41:1330-1334 DOI 10.1038/ng.483.

Cosnes J, Gower-Rousseau C, Seksik P, and Cortot A. 2011. Epidemiology and natural history of inflammatory bowel diseases. Gastroenterology 140:1785-1794 DOI 10.1053/j.gastro.2011.01.055.

Danese S, and Fiocchi C. 2011. Ulcerative colitis. N Engl J Med 365:1713-1725 DOI 10.1056/NEJMra1102942.

Dignass A, Lindsay JO, Sturm A, Windsor A, Colombel JF, Allez M, D'Haens G, D'Hoore A, Mantzaris G, Novacek G, Oresland T, Reinisch W, Sans M, Stange E, Vermeire S, Travis S, and Van Assche G. 2012. Second European evidence-based consensus on the diagnosis and management of ulcerative colitis part 2: current management. J Crohns Colitis 6:991-1030 DOI 10.1016/j.crohns.2012.09.002.

Elkjaer ML, Nejsum LN, Gresz V, Kwon TH, Jensen UB, Frokiaer J, and Nielsen S. 2001. Immunolocalization of aquaporin-8 in rat kidney, gastrointestinal tract, testis, and airways. Am J Physiol Renal Physiol 281:F1047-1057 DOI 10.1152/ajprenal.0158.2001.

Englund G, Jacobson A, Rorsman F, Artursson P, Kindmark A, and Ronnblom A. 2007. Efflux transporters in ulcerative colitis: decreased expression of BCRP (ABCG2) and Pgp (ABCB1). Inflamm Bowel Dis 13:291-297 DOI 10.1002/ibd.20030.

Fanjul-Fernandez M, Folgueras AR, Cabrera S, and Lopez-Otin C. 2009.Matrix metalloproteinases: evolution, gene regulation and functional analysis in mouse models. Biochim Biophys Acta 1803:3-19 DOI 10.1016/j.bbamcr.2009.07.004.

Feng J, Gao Q, Liu Q, Wang F, Lin X, Zhao Q, Liu J, and Li J. 2017. Integrated strategy of differentially expressed genes associated with ulcerative colitis. Mol Med Rep 16:7479-7489 DOI 10.3892/mmr.2017.7509. 
Fukui H, Sekikawa A, Tanaka H, Fujimori Y, Katake Y, Fujii S, Ichikawa K, Tomita S, Imura J, Chiba T, and Fujimori T. 2011. DMBT1 is a novel gene induced by IL-22 in ulcerative colitis. Inflamm Bowel Dis 17:1177-1188 DOI 10.1002/ibd.21473.

Gentleman RC, Carey VJ, Bates DM, Bolstad B, Dettling M, Dudoit S, Ellis B, Gautier L, Ge Y, Gentry J, Hornik K, Hothorn T, Huber W, lacus S, Irizarry R, Leisch F, Li C, Maechler M, Rossini AJ, Sawitzki G, Smith C, Smyth G, Tierney L, Yang JY, and Zhang J. 2004. Bioconductor: open software development for computational biology and bioinformatics. Genome Biol 5:R80 DOI 10.1186/gb-2004-5-10-r80.

Herr R, Halbach S, Heizmann M, Busch H, Boerries M, and Brummer T. 2018. BRAF inhibition upregulates a variety of receptor tyrosine kinases and their downstream effector Gab2 in colorectal cancer cell lines. Oncogene 37:1576-1593 DOI 10.1038/s41388-017-0063-5.

Hirayama I, Ide M, Asao T, and Kuwano H. 2007. Receptor protein tyrosine kinase Ron is highly expressed in colorectal mucosa of ulcerative colitis patients. Hepatogastroenterology 54:16721675.

Jostins L, Ripke S, Weersma RK, Duerr RH, McGovern DP, Hui KY, Lee JC, Schumm LP, Sharma Y, Anderson CA, Essers J, Mitrovic M, Ning K, Cleynen I, Theatre E, Spain SL, Raychaudhuri S, Goyette P, Wei Z, Abraham C, Achkar JP, Ahmad T, Amininejad L, Ananthakrishnan AN, Andersen V, Andrews JM, Baidoo L, Balschun T, Bampton PA, Bitton A, Boucher G, Brand S, Buning C, Cohain A, Cichon S, D'Amato M, De Jong D, Devaney KL, Dubinsky M, Edwards C, Ellinghaus D, Ferguson LR, Franchimont D, Fransen K, Gearry R, Georges M, Gieger C, Glas J, Haritunians T, Hart A, Hawkey C, HedI M, Hu X, Karlsen TH, Kupcinskas L, Kugathasan S, Latiano A, Laukens D, Lawrance IC, Lees CW, Louis E, Mahy G, Mansfield J, Morgan AR, Mowat C, Newman W, Palmieri O, Ponsioen CY, Potocnik U, Prescott NJ, Regueiro M, Rotter JI, Russell RK, Sanderson JD, Sans M, Satsangi J, Schreiber S, Simms LA, Sventoraityte J, Targan SR, Taylor KD, Tremelling M, Verspaget HW, De Vos M, Wijmenga C, Wilson DC, Winkelmann J, Xavier RJ, Zeissig S, Zhang B, Zhang CK, Zhao H, International IBDGC, Silverberg MS, Annese V, Hakonarson H, Brant SR, Radford-Smith G, Mathew CG, Rioux JD, Schadt EE, Daly MJ, Franke A, Parkes M, Vermeire S, Barrett JC, and Cho JH. 2012. Host-microbe interactions have shaped the genetic architecture of inflammatory bowel disease. Nature 491:119-124 DOI 10.1038/nature11582.

Kobayashi T, Mitsuyama K, Yamasaki H, Masuda J, Takedatsu H, Kuwaki K, Yoshioka S, Nagayama K, and Sata M. 2013. Microarray analyses of peripheral whole blood cells from ulcerative colitis patients: effects of leukocytapheresis. Int J Mol Med 31:789-796 DOI 10.3892/ijmm.2013.1270.

Kolde R, Laur S, Adler P, and Vilo J. 2012. Robust rank aggregation for gene list integration and metaanalysis. Bioinformatics 28:573-580 DOI 10.1093/bioinformatics/btr709. 
lancu OD, Colville A, Oberbeck D, Darakjian P, McWeeney SK, and Hitzemann R. 2015. Cosplicing network analysis of mammalian brain RNA-Seq data utilizing WGCNA and Mantel correlations. Front Genet 6:174 DOI 10.3389/fgene.2015.00174.

Langfelder $\mathbf{P}$, and Horvath S. 2008. WGCNA: an R package for weighted correlation network analysis. BMC Bioinformatics 9:559 DOI 10.1186/1471-2105-9-559.

Latella G, Rogler G, Bamias G, Breynaert C, Florholmen J, Pellino G, Reif S, Speca S, and Lawrance IC. 2014.Results of the 4th scientific workshop of the ECCO (I): pathophysiology of intestinal fibrosis in IBD. J Crohns Colitis 8:1147-1165 DOI 10.1016/j.crohns.2014.03.008.

Lawrance IC, Fiocchi C, and Chakravarti S. 2001. Ulcerative colitis and Crohn's disease: distinctive gene expression profiles and novel susceptibility candidate genes. Hum Mol Genet 10:445-456 DOI 10.1093/hmg/10.5.445.

Leal RF, Ayrizono MLS, Milanski M, Coope A, Fagundes JJ, Velloso LA, and Coy CSR. 2010.Activation of signal transducer and activator of transcription-1 (STAT-1) and differential expression of interferon-gamma and anti-inflammatory proteins in pelvic ileal pouches for ulcerative colitis and familial adenomatous polyposis. Clin Exp Immunol 160:380-385.

Leek JT, Johnson WE, Parker HS, Jaffe AE, and Storey JD. 2012. The sva package for removing batch effects and other unwanted variation in high-throughput experiments. Bioinformatics 28:882-883 DOI 10.1093/bioinformatics/bts034.

Lin X, Li J, Zhao Q, Feng JR, Gao Q, and Nie JY. 2018. WGCNA Reveals Key Roles of IL8 and MMP-9 in Progression of Involvement Area in Colon of Patients with Ulcerative Colitis. Curr Med Sci 38:252-258 DOI 10.1007/s11596-018-1873-6.

Liu JZ, van Sommeren S, Huang H, Ng SC, Alberts R, Takahashi A, Ripke S, Lee JC, Jostins L, Shah T, Abedian S, Cheon JH, Cho J, Dayani NE, Franke L, Fuyuno Y, Hart A, Juyal RC, Juyal G, Kim WH, Morris AP, Poustchi H, Newman WG, Midha V, Orchard TR, Vahedi H, Sood A, Sung JY, Malekzadeh R, Westra HJ, Yamazaki K, Yang SK, International Multiple Sclerosis Genetics C, International IBDGC, Barrett JC, Alizadeh BZ, Parkes M, Bk T, Daly MJ, Kubo M, Anderson CA, and Weersma RK. 2018. Association analyses identify 38 susceptibility loci for inflammatory bowel disease and highlight shared genetic risk across populations. Nat Genet 47:979-986 DOI 10.1038/ng.3359.

Loftus EV, Jr. 2004. Clinical epidemiology of inflammatory bowel disease: Incidence, prevalence, and environmental influences. Gastroenterology 126:1504-1517. 
Lu X, Ye K, Zou K, and Chen J. 2014. Identification of copy number variation-driven genes for liver cancer via bioinformatics analysis. Oncol Rep 32:1845-1852

$\mathrm{DOI}$ 10.3892/or.2014.3425

MacFie TS, Poulsom R, Parker A, Warnes G, Boitsova T, Nijhuis A, Suraweera N, Poehlmann A, Szary J, Feakins R, Jeffery R, Harper RW, Jubb AM, Lindsay JO, and Silver A. 2014. DUOX2 and DUOXA2 form the predominant enzyme system capable of producing the reactive oxygen species $\mathrm{H} 2 \mathrm{O} 2$ in active ulcerative colitis and are modulated by 5 -aminosalicylic acid. Inflamm Bowel Dis 20:514-524 DOI 10.1097/01.MIB.0000442012.45038.0e.

Malik TA. 2015. Inflammatory Bowel Disease: Historical Perspective, Epidemiology, and Risk Factors. Surg Clin North Am 95:1105-1122 DOI 10.1016/j.suc.2015.07.006.

Marques FZ, Campain AE, Yang YH, and Morris BJ. 2010.Meta-analysis of genome-wide gene expression differences in onset and maintenance phases of genetic hypertension. Hypertension 56:319-324 DOI 10.1161/HYPERTENSIONAHA.110.155366.

Martinelli M, Strisciuglio C, Veres G, Paerregaard A, Pavic AM, Aloi M, Martin-de-Carpi J, Levine A, Turner D, Del Pezzo M, Staiano A, Miele E, Porto Ibd Working Group of European Society for Pediatric Gastroenterology H, and Nutrition.2014.Clostridium difficile and pediatric inflammatory bowel disease: a prospective, comparative, multicenter, ESPGHAN study. Inflamm Bowel Dis 20:2219-2225 DOI 10.1097/MIB.0000000000000219.

McGovern DP, Gardet A, Torkvist L, Goyette P, Essers J, Taylor KD, Neale BM, Ong RT, Lagace C, Li C, Green T, Stevens CR, Beauchamp C, Fleshner PR, Carlson M, D'Amato M, Halfvarson J, Hibberd ML, Lordal M, Padyukov L, Andriulli A, Colombo E, Latiano A, Palmieri O, Bernard EJ, Deslandres C, Hommes DW, de Jong DJ, Stokkers PC, Weersma RK, Sharma Y, Silverberg MS, Cho JH, Wu J, Roeder K, Brant SR, Schumm LP, Duerr RH, Dubinsky MC, Glazer NL, Haritunians T, Ippoliti A, Melmed GY, Siscovick DS, Vasiliauskas EA, Targan SR, Annese V, Wijmenga C, Pettersson S, Rotter JI, Xavier RJ, Daly MJ, Rioux JD, and Seielstad M. 2010. Genome-wide association identifies multiple ulcerative colitis susceptibility loci. Nat Genet 42:332-337 DOI 10.1038/ng.549.

McKaig BC, McWilliams D, Watson SA, and Mahida YR. 2003. Expression and regulation of tissue inhibitor of metalloproteinase-1 and matrix metalloproteinases by intestinal myofibroblasts in inflammatory bowel disease. Am J Pathol DOI 162:1355-136010.1016/S0002-9440(10)63931-4.

Min M, Peng LH, Sun G, Guo MZ, Qiu ZW, and Yang YS. 2013.Aquaporin 8 expression is reduced and regulated by microRNAs in patients with ulcerative colitis. Chin Med J (Engl) 126:1532-1537. 
Noble CL, Abbas AR, Cornelius J, Lees CW, Ho GT, Toy K, Modrusan Z, Pal N, Zhong F, Chalasani S, Clark H, Arnott ID, Penman ID, Satsangi J, and DiehI L. 2008. Regional variation in gene expression in the healthy colon is dysregulated in ulcerative colitis. Gut 57:1398-1405 DOI 10.1136/gut.2008.148395.

Noisakran S, and Carr DJ. 2001. Type I interferons and herpes simplex virus infection: a naked DNA approach as a therapeutic option? Immunol Res 24:1-11 DOI 10.1385/IR:24:1:01.

Planell N, Lozano JJ, Mora-Buch R, Masamunt MC, Jimeno M, Ordas I, Esteller M, Ricart E, Pique JM, Panes J, and Salas A. 2013.Transcriptional analysis of the intestinal mucosa of patients with ulcerative colitis in remission reveals lasting epithelial cell alterations. Gut 62:967-976 DOI 10.1136/gutjnl-2012-303333.

Prom-On S, Chanthaphan A, Chan JH, and Meechai A. 2010. Enhancing biological relevance of a weighted gene co-expression network for functional module identification. J Bioinform Comput Biol 9:111-129.

Ritchie ME, Phipson B, Wu D, Hu Y, Law CW, Shi W, and Smyth GK. 2015. limma powers differential expression analyses for RNA-sequencing and microarray studies. Nucleic Acids Res 43:e47 DOI 10.1093/nar/gkv007.

Rung J, and Brazma A. 2017. Reuse of public genome-wide gene expression data. Nat Rev Genet 14:89-99 DOI 10.1038/nrg3394.

Seifuddin F, Pirooznia M, Judy JT, Goes FS, Potash JB, and Zandi PP.2013. Systematic review of genome-wide gene expression studies of bipolar disorder. BMC Psychiatry 13:213 DOI 10.1186/1471-244X-13-213.

Shukla T, Singh S, Loftus EV, Jr., Bruining DH, and McCurdy JD. 2015. Antiviral Therapy in Steroidrefractory Ulcerative Colitis with Cytomegalovirus: Systematic Review and Meta-analysis. Inflamm Bowel Dis 21:2718-2725 DOI 10.1097/MIB.0000000000000489.

Singh S, Graff LA, and Bernstein CN. 2009. Do NSAIDs, antibiotics, infections, or stress trigger flares in IBD? Am J Gastroenterol 104:1298-1313 DOI 10.1038/ajg.2009.15.

Song R, Li Y, Hao W, Wang B, Yang L, and Xu F. 2018. Identification and analysis of key genes associated with ulcerative colitis based on DNA microarray data. Medicine (Baltimore) 97:e10658 DOI 10.1097/md.0000000000010658.

Stallhofer J, Friedrich M, Konrad-Zerna A, Wetzke M, Lohse P, Glas J, Tillack-Schreiber C, Schnitzler F, Beigel F, and Brand S. 2015. Lipocalin-2 Is a Disease Activity Marker in Inflammatory Bowel Disease Regulated by IL-17A, IL-22, and TNF-alpha and Modulated by IL23R Genotype Status. Inflamm Bowel Dis 21:2327-2340

DOI 10.1097/mib.0000000000000515. 
641

642

643

644

645

646

647

648

649

650

651

652

653

654

655

656

657

658

659

660

661

662

663

664

665

666

667

668

669

670

671

672

673

674

Strober W, Fuss I, and Mannon P. 2007. The fundamental basis of inflammatory bowel disease. J Clin Invest 117:514-521 DOI 10.1172/JCI30587.

Sturm A, Leite AZ, Danese S, Krivacic KA, West GA, Mohr S, Jacobberger JW, and Fiocchi C. 2004. Divergent cell cycle kinetics underlie the distinct functional capacity of mucosal T cells in Crohn's disease and ulcerative colitis. Gut 53:1624-1631

DOI 10.1136/gut.2003.033613.

Su C, Zhan G, and Zheng C. 2016. Evasion of host antiviral innate immunity by HSV-1, an update. Virol J 13:38 DOI 10.1186/s12985-016-0495-5.

Tripathi S, Pohl MO, Zhou Y, Rodriguez-Frandsen A, Wang G, Stein DA, Moulton HM, DeJesus P, Che J, Mulder LC, Yanguez E, Andenmatten D, Pache L, Manicassamy B, Albrecht RA, Gonzalez MG, Nguyen Q, Brass A, Elledge S, White M, Shapira S, Hacohen N, Karlas A, Meyer TF, Shales M, Gatorano A, Johnson JR, Jang G, Johnson T, Verschueren E, Sanders D, Krogan N, Shaw M, Konig R, Stertz S, Garcia-Sastre A, and Chanda SK. 2015. Meta- and Orthogonal Integration of Influenza "OMICs" Data Defines a Role for UBR4 in Virus Budding. Cell Host Microbe 18:723-735 DOI 10.1016/j.chom.2015.11.002.

Wang YD, Tan XY, and Zhang K. 2009. Correlation of plasma MMP-1 and TIMP-1 levels and the colonic mucosa expressions in patients with ulcerative colitis. Mediators Inflamm 2009:275072 DOI $10.1155 / 2009 / 275072$.

Wang YD, and Yan PY. 2006. Expression of matrix metalloproteinase-1 and tissue inhibitor of metalloproteinase-1 in ulcerative colitis. World J Gastroenterol 12:6050-6053.

Wettenhall JM, and Smyth GK. 2004. limmaGUI: a graphical user interface for linear modeling of microarray data. Bioinformatics 20:3705-3706 DOI 10.1093/bioinformatics/bth449.

Wu F, Dassopoulos T, Cope L, Maitra A, Brant SR, Harris ML, Bayless TM, Parmigiani G, and Chakravarti S. 2007. Genome-wide gene expression differences in Crohn's disease and ulcerative colitis from endoscopic pinch biopsies: insights into distinctive pathogenesis. Inflamm Bowel Dis 13:807-821 DOI 10.1002/ibd.20110.

Wynn TA, and Ramalingam TR. 2012. Mechanisms of fibrosis: therapeutic translation for fibrotic disease. Nat Med 18:1028-1040 DOI 10.1038/nm.2807.

Xie D, Zhang Y, and Qu H. 2018.Crucial genes of inflammatory bowel diseases explored by gene expression profiling analysis. Scand J Gastroenterol 53:685-691

DOI 10.1080/00365521.2018.1461923.

Yan S, Wang W, Gao G, Cheng M, Wang X, Wang Z, Ma X, Chai C, and Xu D. 2018.Key genes and functional coexpression modules involved in the pathogenesis of systemic lupus erythematosus. $J$ Cell Physiol233(11):8815-8825 DOI 10.1002/jcp.26795. 
675 Yashiro M. 2014. Ulcerative colitis-associated colorectal cancer. World J Gastroenterol 20:16389-16397

676 DOI 10.3748/wjg.v20.i44.16389.

Zahn A, Moehle C, Langmann T, Ehehalt R, Autschbach F, Stremmel W, and Schmitz G. 2007. Aquaporin-8 expression is reduced in ileum and induced in colon of patients with ulcerative colitis. World J Gastroenterol 13:1687-1695.

Zhang B, and Horvath S. 2005. A general framework for weighted gene co-expression network analysis. Stat Appl Genet Mol Biol 4:Article17 DOI 10.2202/1544-6115.1128. Biotech Histochem 91:269-276 DOI 10.3109/10520295.2016.1144079. 


\section{Table $\mathbf{1}$ (on next page)}

Table 1 Summary of those 14 genome-wide gene expression datasets involving UC patients 
1 Table 1 Summary of those 14 genome-wide gene expression datasets involving UC patients

\begin{tabular}{|c|c|c|c|c|c|c|c|}
\hline & $\begin{array}{l}\text { Gene Expression } \\
\text { Omnibus Series } \\
\text { (GSE) number }\end{array}$ & $\begin{array}{l}\text { Samples } \\
\text { (UC } \\
\text { patients/co } \\
\text { ntrols) }\end{array}$ & Source types & $\begin{array}{l}\text { Gene Expression } \\
\text { Platform } \\
\text { (GPL) }\end{array}$ & Omnibus & Data file type & PMID \\
\hline 1 & GSE9452 & $8 / 5$ & colonic biopsies & GPL570 & & Raw data(.CEL) & 19177426 \\
\hline 2 & GSE10714 & $3 / 3$ & colonic biopsies & GPL570 & & Raw data(.CEL) & 20087348 \\
\hline 3 & GSE13367 & $16 / 20$ & colonic biopsies & GPL570 & & Raw data(.CEL) & 19834973 \\
\hline 4 & GSE14580 & $24 / 6$ & colonic biopsies & GPL570 & & Raw data(.CEL) & 19700435 \\
\hline 5 & GSE22619 & $10 / 10$ & sigmoid colon & GPL570 & & Raw data(.CEL) & 21621540 \\
\hline 6 & GSE36807 & $15 / 7$ & colon pinch biopsies & GPL570 & & Raw data(.CEL) & 24155895 \\
\hline 7 & GSE38713 & $22 / 13$ & colonic biopsies & GPL570 & & Raw data(.CEL) & 23135761 \\
\hline 8 & GSE47908 & $45 / 15$ & colonic biopsies & GPL570 & & Raw data(.CEL) & 25358065 \\
\hline 9 & GSE73661 & $67 / 12$ & colonic biopsies & GPL6244 & & Raw data(.CEL) & 27802155 \\
\hline 10 & GSE59071 & $74 / 11$ & colonic biopsies & GPL6244 & & Raw data(.CEL) & 26313692 \\
\hline 11 & GSE48958 & $7 / 8$ & colonic biopsies & GPL6244 & & Raw data(.CEL) & 25546151 \\
\hline 12 & GSE6731 & $5 / 4$ & $\begin{array}{l}\text { Cecum, Sigmoid, } \\
\text { Rectum colon }\end{array}$ & GPL8300 & & Raw data(.CEL) & 17262812 \\
\hline 13 & GSE53306 & $16 / 12$ & Colon tissue & GPL14951 & & $\begin{array}{l}\text { Matrix File } \\
\text { (non- } \\
\text { normalized.txt) }\end{array}$ & 26034135 \\
\hline 14 & GSE65114 & $16 / 12$ & colonic biopsies & GPL16686 & & Raw data(.CEL) & NULL \\
\hline
\end{tabular}

2 


\section{Table 2 (on next page)}

Table 2 Pathway and Process Enrichment Analysis of those functional coexpression modules in UC 
1 Table 2 Pathway and Process Enrichment Analysis of those functional coexpression modules in UC

\begin{tabular}{|c|c|c|c|c|c|c|c|}
\hline Modules & GO & Category & Description & Count & $\%$ & $\log 10(\mathrm{P})$ & $\log 10(q)$ \\
\hline \multirow{10}{*}{ Blue } & GO:0030198 & GO Biological Processes & extracellular matrix organization & 121 & 7.05 & -49.41 & -45.10 \\
\hline & GO:0046649 & GO Biological Processes & lymphocyte activation & 177 & 10.31 & -48.76 & -44.75 \\
\hline & GO:0048514 & GO Biological Processes & blood vessel morphogenesis & 166 & 9.67 & -45.01 & -41.40 \\
\hline & GO:0050900 & GO Biological Processes & leukocyte migration & 123 & 7.16 & -35.59 & -32.42 \\
\hline & GO:0006954 & GO Biological Processes & inflammatory response & 152 & 8.85 & -29.70 & -26.66 \\
\hline & GO:0001816 & GO Biological Processes & cytokine production & 143 & 8.33 & -28.99 & -25.98 \\
\hline & GO:0019221 & GO Biological Processes & cytokine-mediated signaling pathway & 145 & 8.44 & -27.99 & -25.04 \\
\hline & GO:0009611 & GO Biological Processes & response to wounding & 132 & 7.69 & -25.97 & -23.19 \\
\hline & R-HSA-109582 & Reactome Gene Sets & Hemostasis & 126 & 7.34 & -25.06 & -22.31 \\
\hline & GO:0002250 & GO Biological Processes & adaptive immune response & 121 & 7.05 & -23.43 & -20.72 \\
\hline \multirow{10}{*}{$\begin{array}{l}\text { Salmon } \\
\text { module }\end{array}$} & R-HSA-913531 & Reactome Gene Sets & Interferon Signaling & 39 & 31.71 & -50.63 & -46.32 \\
\hline & GO:0051607 & GO Biological Processes & defense response to virus & 30 & 24.39 & -32.91 & -29.64 \\
\hline & hsa05168 & KEGG Pathway & Herpes simplex infection & 21 & 17.07 & -21.50 & -18.36 \\
\hline & GO:0001817 & GO Biological Processes & regulation of cytokine production & 29 & 23.58 & -18.62 & -15.55 \\
\hline & R-HSA-1280218 & Reactome Gene Sets & Adaptive Immune System & 29 & 23.58 & -16.47 & -13.54 \\
\hline & GO:0060759 & GO Biological Processes & $\begin{array}{l}\text { regulation of response to cytokine } \\
\text { stimulus }\end{array}$ & 16 & 13.01 & -15.40 & -12.52 \\
\hline & GO:0045088 & GO Biological Processes & regulation of innate immune response & 17 & 13.82 & -11.07 & -8.37 \\
\hline & hsa04621 & KEGG Pathway & NOD-like receptor signaling pathway & 12 & 9.76 & -9.95 & -7.35 \\
\hline & GO:0035455 & GO Biological Processes & response to interferon-alpha & 6 & 4.88 & -9.15 & -6.62 \\
\hline & GO:0019883 & GO Biological Processes & $\begin{array}{l}\text { antigen processing and presentation of } \\
\text { endogenous antigen }\end{array}$ & 6 & 4.88 & -9.01 & -6.49 \\
\hline Green & R-HSA-1640170 & Reactome Gene Sets & Cell Cycle & 100 & 35.46 & -82.79 & -78.48 \\
\hline
\end{tabular}




\begin{tabular}{|c|c|c|c|c|c|c|c|}
\hline & R-HSA-69620 & Reactome Gene Sets & Cell Cycle Checkpoints & 52 & 18.44 & -44.54 & -40.71 \\
\hline & GO:0044770 & GO Biological Processes & cell cycle phase transition & 65 & 23.05 & -44.07 & -40.36 \\
\hline & GO:0051301 & GO Biological Processes & cell division & 66 & 23.40 & -43.83 & -40.22 \\
\hline & GO:0006281 & GO Biological Processes & DNA repair & 53 & 18.79 & -31.28 & -28.20 \\
\hline & GO:0045787 & GO Biological Processes & positive regulation of cell cycle & 40 & 14.18 & -24.29 & -21.50 \\
\hline & GO:0051983 & GO Biological Processes & regulation of chromosome segregation & 24 & 8.51 & -23.76 & -21.00 \\
\hline & GO:0051321 & GO Biological Processes & meiotic cell cycle & 30 & 10.64 & -20.87 & -18.24 \\
\hline & GO:0045786 & GO Biological Processes & negative regulation of cell cycle & 43 & 15.25 & -20.64 & -18.02 \\
\hline & GO:0071103 & GO Biological Processes & DNA conformation change & 30 & 10.64 & -19.39 & -16.81 \\
\hline \multirow{10}{*}{ Cyan } & GO: 1990778 & GO Biological Processes & protein localization to cell periphery & 16 & 7.66 & -8.45 & -4.38 \\
\hline & GO:0002446 & GO Biological Processes & neutrophil mediated immunity & 19 & 9.09 & -6.86 & -3.29 \\
\hline & GO:0030029 & GO Biological Processes & actin filament-based process & 23 & 11.00 & -6.76 & -3.29 \\
\hline & R-HSA-9006934 & 4eactome Gene Sets & $\begin{array}{l}\text { Signaling by Receptor Tyrosine } \\
\text { Kinases }\end{array}$ & 18 & 8.61 & -6.76 & -3.29 \\
\hline & hsa04141 & KEGG Pathway & $\begin{array}{l}\text { Protein processing in endoplasmic } \\
\text { reticulum }\end{array}$ & 10 & 4.78 & -5.56 & -2.59 \\
\hline & GO:0071407 & GO Biological Processes & $\begin{array}{l}\text { cellular response to organic cyclic } \\
\text { compound }\end{array}$ & 18 & 8.61 & -5.30 & -2.38 \\
\hline & GO:1903829 & GO Biological Processes & $\begin{array}{l}\text { positive regulation of cellular protein } \\
\text { localization }\end{array}$ & 13 & 6.22 & -5.28 & -2.38 \\
\hline & hsa05200 & KEGG Pathway & Pathways in cancer & 14 & 6.70 & -4.83 & -2.02 \\
\hline & GO:0033120 & GO Biological Processes & positive regulation of RNA splicing & 5 & 2.39 & -4.77 & -1.98 \\
\hline & hsa04810 & KEGG Pathway & Regulation of actin cytoskeleton & 10 & 4.78 & -4.63 & -1.88 \\
\hline \multirow{4}{*}{ Grey60 } & GO:0002274 & GO Biological Processes & myeloid leukocyte activation & 55 & 35.26 & -45.62 & -41.31 \\
\hline & GO:0006954 & GO Biological Processes & inflammatory response & 50 & 32.05 & -35.05 & -31.69 \\
\hline & GO:0009617 & GO Biological Processes & response to bacterium & 40 & 25.64 & -28.23 & -25.09 \\
\hline & GO:0001816 & GO Biological Processes & cytokine production & 42 & 26.92 & -27.52 & -24.41 \\
\hline
\end{tabular}




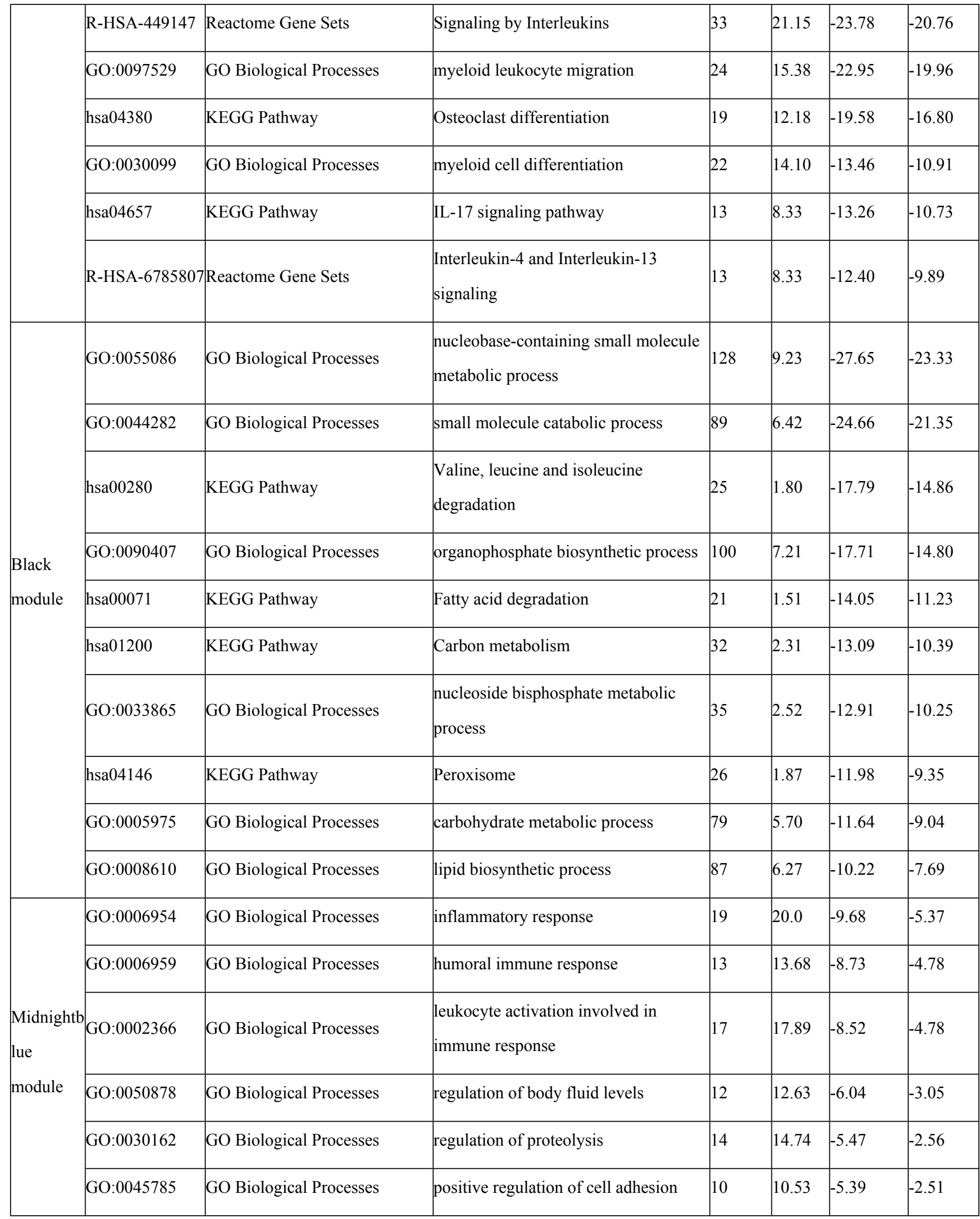




\begin{tabular}{|c|c|c|c|c|c|c|}
\hline R-HSA-6785807 & Reactome Gene Sets & $\begin{array}{l}\text { Interleukin-4 and Interleukin-13 } \\
\text { signaling }\end{array}$ & 6 & 6.32 & -5.27 & -2.42 \\
\hline GO:0010817 & GO Biological Processes & regulation of hormone levels & 11 & 11.58 & -5.10 & -2.31 \\
\hline GO:0045766 & GO Biological Processes & positive regulation of angiogenesis & 7 & 7.37 & -4.74 & -2.06 \\
\hline GO:0001666 & GO Biological Processes & response to hypoxia & 8 & 8.42 & -4.41 & -1.81 \\
\hline
\end{tabular}

2

$3 *$ 'Count' is the number of genes contained in enriched pathway. '\%' is the proportion of the total number 4 of genes in each module. ' $\log 10(P)^{\prime}$ is the $p$-value in $\log$ base $10 .{ }^{\prime} \log 10(q)$ ' is the multi-test adjusted $p$ $5 \quad$ value in log base 10. 
Figure 1

Figure1 Top 50 up-regulated and top 50 down-regulated genes in UC.

The vertical axis shows the gene symbols and the horizontal axis represents dataset or merged datasets from same platform. Yellow indicates decreased expression $(\log \mathrm{FC}<0)$ and purple indicates increased expression $(\log F C>0)$, the darker the color, the greater the difference; numbers in the figure show the logFC of DEGs, which was calculated by the limma package of $R$. 


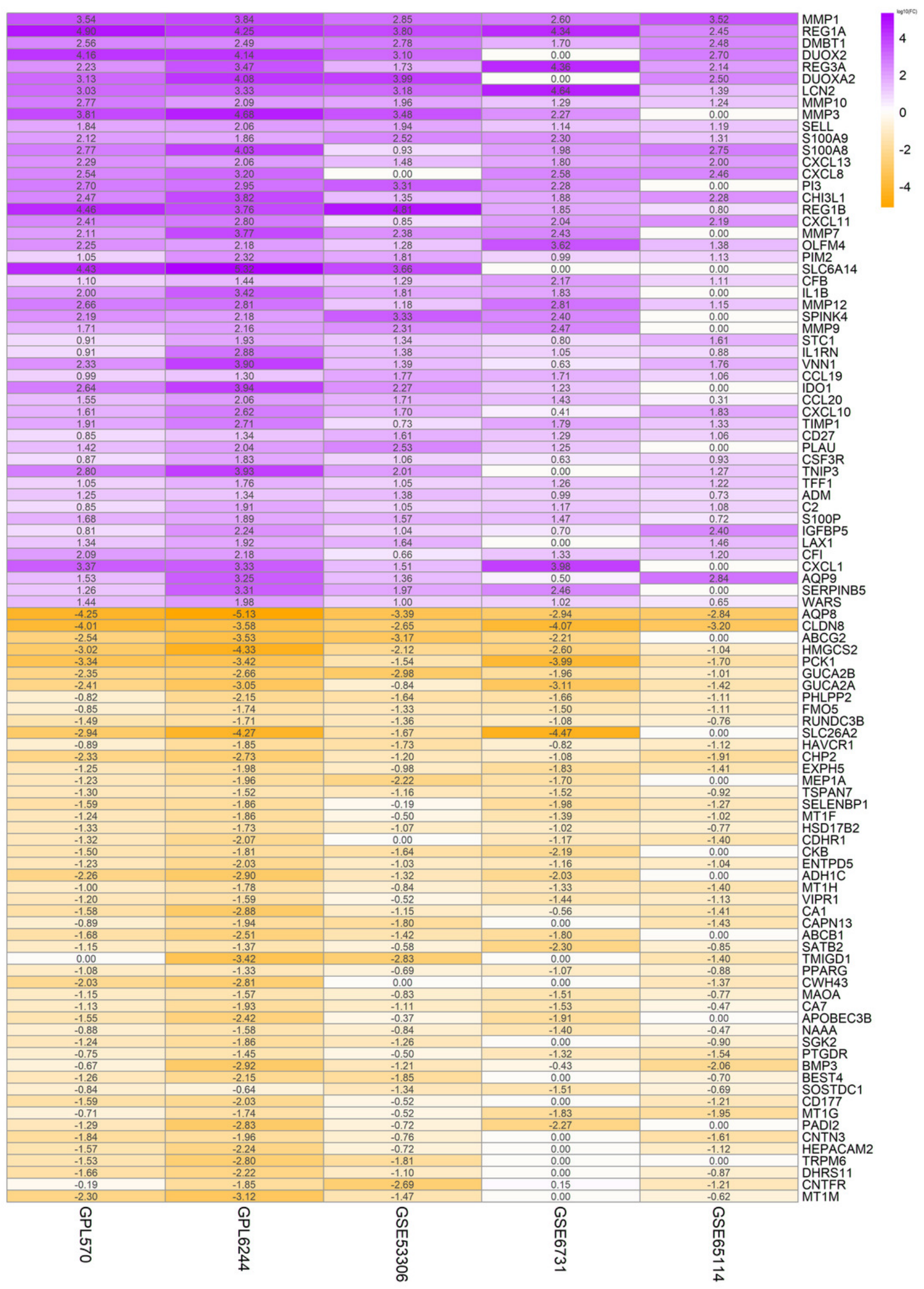




\section{Figure 2}

Figure2 Heat map of the FPKM of the top 100 DEGs from GPL570 samples.

The vertical axis lists the gene symbols and the horizontal axis shows the sample grouping, with orange representing the UC group and blue representing the control group. The gradual change in color from green to red in the heat map shows a gradual increase in FPKM of genes. The heat map can roughly distinguish the UC group from the control group. 


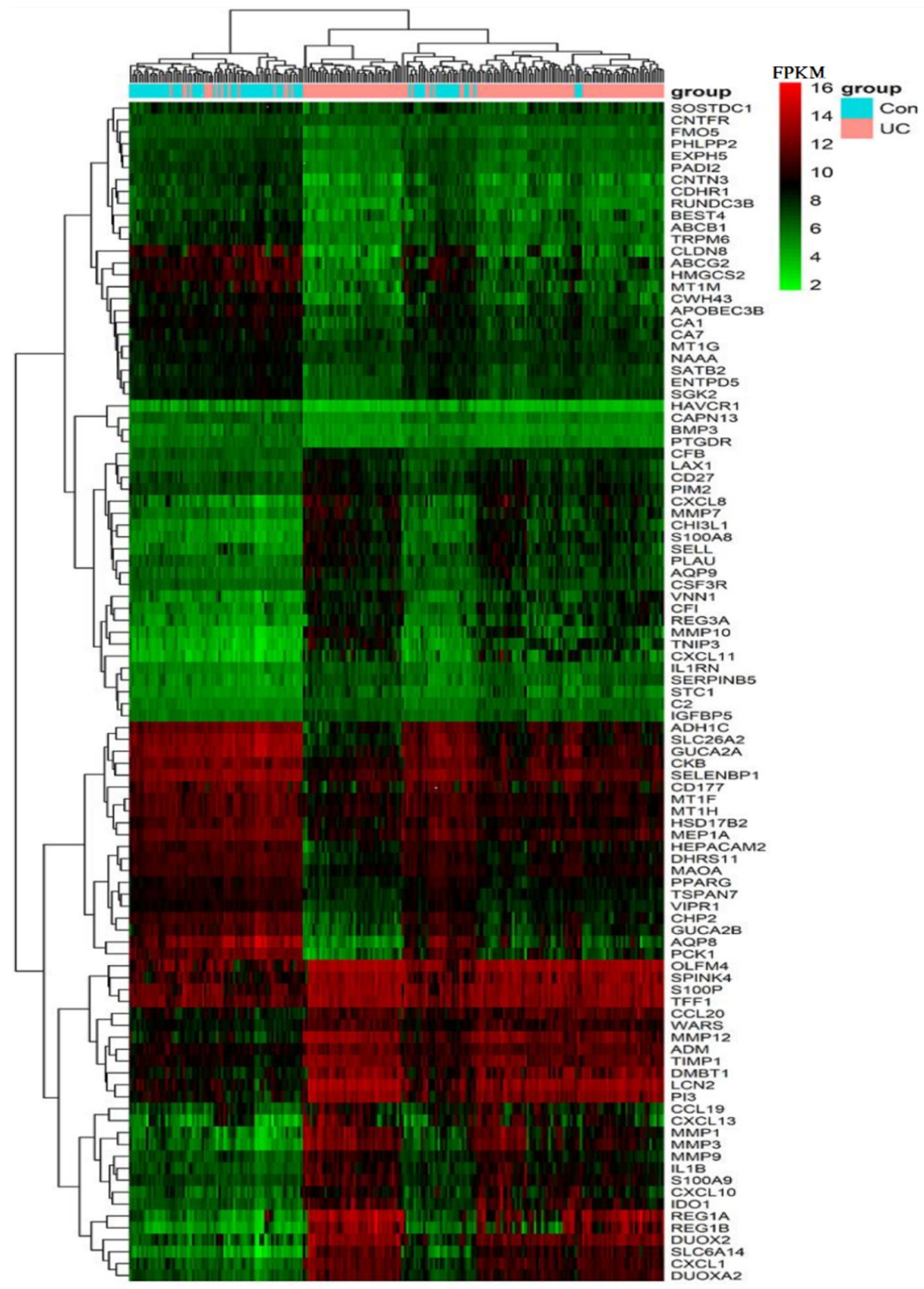




\section{Figure 3}

Figure3 Plots in the WGCNA analysis using gene expressions in 328 UC patients and 138 controls from GPL570 datasets.

(A) Displayed the influence of soft-threshold power on scale-free topology fit index. (B) Showed the influence of soft-threshold power on the mean connectivity. (C) Cluster dendrogram of coexpression genes and functional modules in UC. More than 15 modules were identified by Dynamic Tree Cutting method with a medium sensitivity (minModuleSize=30, deepSplit=2) to branch splitting. Merged Dynamic shows the 7 functional modules obtained by merging similar modules in Dynamic Tree Cut (Height>0.3).

(D) The construction of co-expression modules by WGCNA. Each module was assigned a unique color identifier. The progressively saturated red colors indicated the higher overlap among these functional modules. 

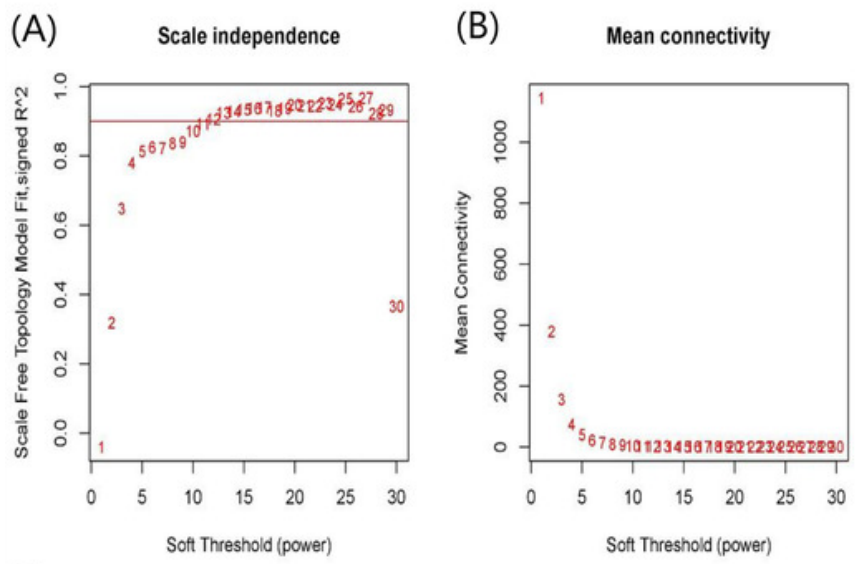

(D)

(C)
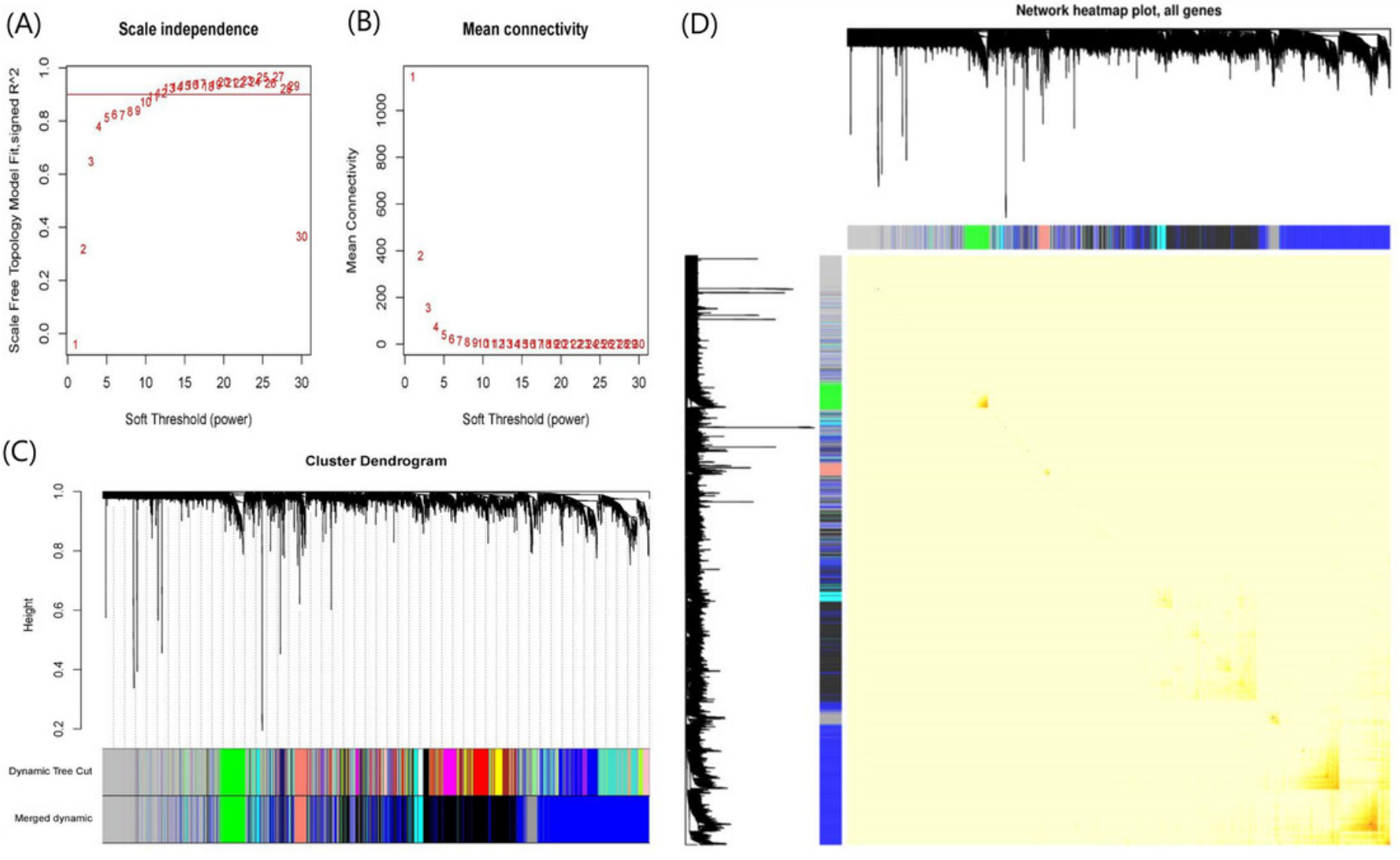